\title{
P045. OnabotulinumtoxinA: long term treatment for chronic migraine with medication overuse
}

\author{
Simona Guerzoni*, Maria Michela Cainazzo, Luigi Alberto Pini \\ From Abstracts from the 1st Joint ANIRCEF-SISC Congress \\ Rome, Italy. 29-31 October 2015
}

\section{Introduction}

Chronic migraine represents the most disabling condition among headaches, in particular when migraine is associated with drug abuse.

Patients with chronic migraine (CM) coming to our centres are difficult to treat, both because of their refractory to antimigraine prophylactic treatment and for the combination of several comorbidities, that often need a multidisciplinary approach that leads to a multi-prescription of drugs.

The treatment with OnabotulinumtoxinA $\left(\right.$ Botox $\left.^{\circledR}\right)$ is an important therapeutic option both for its efficacy in the long term, and for the safety profile, due to the lack of clinically significant side effects.

\section{Materials and methods}

In our Headache Centre we performed a retrospective study including a sample of 67 patients with a diagnosis of $\mathrm{CM}$ associated with drug abuse according to the ICHD-III (beta) classification. The patients were treated with OnabotulinumtoxinA according to the paradigm of the PREEMPT study (155 U to 31 injection sites) [1].

The purpose of our study was to evaluate the duration of the Botox's efficacy in terms of headache days (HD), analgesic consumption (AC) and to assess the patients' quality of life by some self-administered scales (SF-36, HIT-6) and pain scale (VAS) [2].

We recorded medical charts for 67 patients. However, we report the data concerning the results of only 57 patients since they represent the ones who were injected regularly every 3 months without interruption, some of them being injected up to cycle 7 . Ten patients discontinued for regulatory reasons.

\footnotetext{
* Correspondence: simona_guerzoni@libero.it

Headache and Drug Abuse Inter-Department Research Centre, University of
} Modena e Reggio Emilia, Modena, Italy
Legend:

(ANOVA)

$\mathrm{HD}=$ Headache days

AC $=$ Analgesic Consumption

HIT-6 = Headache Impact Test

SF-36 = Short-Form Health Survey (Physical and Mental)

VAS $=$ Visual Analogue Scale

\section{Results}

Positive trend of the effectiveness of the treatment appears to be significant in all parameters evaluated as shown in the table 1.

\section{Conclusions}

This retrospective study confirms the safety and tolerability profile of repeated treatment with Onabotulinumtoxin A and shows a good consistency of the therapeutic effect over one year of treatment. The trend of the clinical parameters suggests other studies to further investigate the long-term efficacy of the treatment, as recently suggested by Pascual [3].

Moreover, it is important to outline that in our sample we did not register any clinically relevant side effect, besides slight pain in the site of injection, and two cases of transient hypotension during the injection protocol, spontaneously reversed.

Written informed consent to publish was obtained from the patient(s). 


\section{References}

1. Diener HC, Dodick DW, Aurora SK, Turkel CC, DeGryse RE, Lipton RB, et al: OnabotulinumtoxinA for treatment of chronic migraine: Results from the double-blind, randomized, placebo-controlled phase of the PREEMPT 2 trial. Cephalalgia 2010, 30(7):804-814.

2. Apolone G, Mosconi P: The Italian SF-36 Health Survey: translation, validation and norming. J Clin Epidemiol 1998, 51(11):1025-1036.

3. Cernuda-Morollón E, Ramón C, Larrosa D, Alvarez R, Riesco N, Pascual J: Long-term experience with onabotulinumtoxinA in the treatment of chronic migraine: What happens after one year? Cephalalgia 2015, 35(19):864-868.

doi:10.1186/1129-2377-16-S1-A183

Cite this article as: Guerzoni et al:: P045. OnabotulinumtoxinA: long term treatment for chronic migraine with medication overuse. The Journal of Headache and Pain 2015 16(Suppl 1):A183.

\section{Submit your manuscript to a SpringerOpen ${ }^{\mathcal{O}}$ journal and benefit from:}

- Convenient online submission

- Rigorous peer review

- Immediate publication on acceptance

- Open access: articles freely available online

- High visibility within the field

- Retaining the copyright to your article 